\title{
Taşkın ve Rüsubat Kontrolünde Yeni Öneri: Gemiburnu Tip Geçirgen Bent
}

\author{
Emre AKÇALI ${ }^{1}$
}

Öz

Dağlık havzalarda ciddi hasarlara ve can kaybına neden olan taşkın olayları, büyük ölçüde taşkın sırasında köprü ve menfezleri tıkayan odunsu malzemenin taşınmasıyla meydana gelmektedir. Son yıllarda, odunsu malzemeleri tuzaklamak üzere geçirgen tersip bentleri inşa edilmeye başlanmıştır. Ancak, bu yapılar özellikle büyük taşkınlarda odunsu malzemelerle kısa sürede tıkanabilmekte, bu nedenle malzeme filtreleme ve odunsu materyali tuzaklama işlevini hızla kaybetmektedir. Bu çalışmada, bu sorunun önlenmesi adına gemiburnu şeklinde tasarlanmış yeni tip bent, işletme halindeki iki farklı tipteki klasik yarı geçirgen tersip bendi ile laboratuvar ortamında karşılaştırılmıştır. Sonuçlar yeni tipin hızlı tıkanma ve üstten aşma sorununa karşı etkili olduğunu göstermiştir. Bu yapının uygulanmasıyla taşkın zararlarının azaltılması adına önemli bir katkı sağlanmış olacaktır.

Anahtar Kelimeler: Geçirgen tersip bendi, odunsu malzeme, gemiburnu, yarı geçirgen, taşkın, rüsubat kontrolü.

\section{ABSTRACT \\ New Approach to Control Flood and Transport of Debris Material: Shipnose Type Open Check Dam}

Flood events, which cause serious damage and loss of life in mountainous basins, are mostly caused by the transport of woody material that blocks bridges and culverts during flooding. In recent years, open check dams have begun to be built to trap woody materials. However, these structures can become blocked with woody materials in a short time, especially in large floods. So the material quickly loses its function of filtering and trapping the woody material. In this study, in order to prevent this problem, the new type of dam designed in the shape of the ship nose was compared against two different types of classical semi permeable open check dams in operation, in a laboratory. The results showed that the new type is effective against the problem of rapid clogging and overrun of woody materials. With the

\footnotetext{
Not: Bu yazı

- Yayın Kurulu'na 15 Şubat 2021 günü ulaşmıştır. 25 Ağustos 2021 günü yayımlanmak üzere kabul edilmiştir.

- 31 Ocak 2023 gününe kadar tartışmaya açıktır.

- https://doi.org/10.18400/tekderg.880224
}

1 Devlet Su İşleri 22. Bölge Müdürlüğ̈̈, Trabzon - emreakcali@dsi.gov.tr https://orcid.org/0000-0002-4825-7265 
implementation of this structure, an important contribution could be made to reduce flood damages.

Keywords: Open check dam, woody debris, ship nose, semi permeable, flood, debris control.

\section{GíRiș}

Türkiye'nin nehir havzalarında oldukça fazla taşkın olayları meydana gelmekte ve taşkınlar özellikle yoğun yağışların sık görüldüğü Doğu Karadeniz Havzası'nda (DKH) çok fazla can ve mal kayıplarına sebep olmaktadır [1,2]. Taşkınlar, yağış-akış miktarı ve dere yatağı kesiti dışında çok önemli başka bir parametre olan rüsubattan da tetiklenirler. Oluştuğu yerden çökeldiği yere kadar suda asılı halde veya tabanda sürüntü maddesi olarak su tarafından taşınan katı maddeler olarak tanımlanan rüsubat, kilden iri bloklara kadar zemin türlerini kapsarken, aynı zamanda kök, ağaç ve dallar gibi odunsu materyalleri de içermektedir. Yüksek eğime sahip vadiler ve dere yatakları, kayma potansiyeli yüksek jeolojik yapıya sahip yamaçlar, kıyı oyulmasına uygun yamaç topukları ve sığ köke sahip bitki örtüsü gibi etmenler, yukarı havzalarda oluşabilecek rüsubat hareketinin ana nedenleridir. Yüksek yağış rejimi ile de birleşen bu tip yerlerde; dere yatağına kayan zemin malzemeleri ve odunsu materyal barındıran heyelan kütlesi, kıyı oyulmasıyla oluşan sediment birikimi, yatak içerisinde doğal olarak yetişen ağaçlar ve bitkiler uygun akış koşullarıyla birlikte mansaba ilerlerler [3]. Özellikle rüsubi harekete sahip bu dağlık havzaların memba kesimlerinden hareketlenen bu malzemeler, mansapta dere geçiş yapıları (köprü, menfez, büz vb.) başta olmak üzere kapalı kesitlerde ve hatta ıslahlı kesitlerde tıkanmalara neden olurlar (Şekil 1). Bunun sonucunda ise çoğu zaman hasarsız atlatılabilecek olan akışlar, kesitten taşarak öngörülemeyen taşkınlara dönüşürler. Bundan dolayı, taşkın yönetiminde sadece akarsuların debisine göre kesit belirlenmesi ve uygulanması yeterli olmamaktadır. Bu bağlamda taşkın kontrolü için yukarı havza rüsubat durumunun incelenmesi ve gerekli önlemlerin buna göre alınması gerekmektedir.
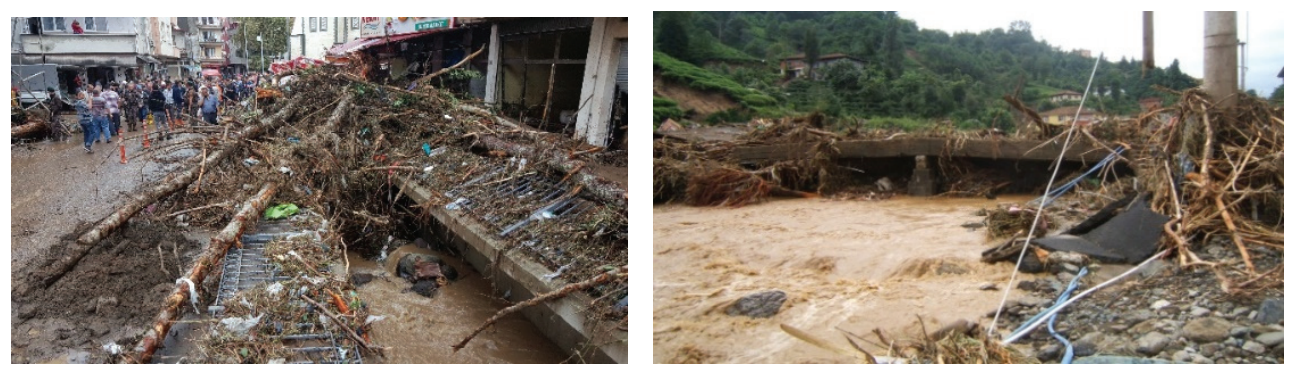

Şekil 1 - Doğu Karadeniz Havzası'nda taşkın anında biriken sediment ve odunsu malzemenin köprü vb. yapıların kesitlerini tıkaması (Trabzon Beşikdüzü İlçesi ve Rize Iyidere Illçesi Taşkınları)

Yukarı havza önlemleri için, özellikle Doğu Karadeniz Havzası gibi dağlık nehir havzalarında uygulanan başlıca yapılar; sel kapanları, eğim düzenleyen britler, taban malzemesini yerinde tutmayı amaçlayan taban kuşakları, heyelanlara topuk olan ve eğim düzenleyen islah sekileri ve sediment tutmayı amaçlayan tersip bentleridir. Ancak tersip 
bentlerinin odunsu materyali tutamamasından hareketle son yıllarda dünyada geliştirilen yapı genellikle filtreleme özelliği gösteren demir profilli izgara ve beton ayaklar ile oluşturulmuş geçirgen tersip bentleri olmuştur. Geçirgen tersip bentleri, özellikle büyük taşkınlar sırasında taşınan odunsu malzeme, sediment vb. rüsubi malzemeyi kontrol ederek bir nehir havzasının yönetimi ve geliştirilmesinde önemli rol oynarlar [4]. Sedimentler, düşük akımlarda bent aralıklarından geçerken, büyük akımlarda memba tarafında birikme meydana gelir [5]. Bu yapılar, belli çaptaki malzemenin geçişine imkân vererek akarsu yatağının beslenmesini ve doğal yapısını korumasını sağlamakta, bu şekilde mansap tarafındaki oyulmaları da önlemektedir. Aynı zamanda iri malzemelerin taşkın anında tutulmasını sağlayarak mansapta yer alan köprü, menfez gibi sanat yapılarının tıkanması engelleyerek taşkın zararlarını önemli ölçüde azaltmaktadır [6,7]. Bu olgu, geçirgen bentlerin kendi kendini temizlemesi (selfcleaning) ve birikim tahkimat işlemi (deposit armoring processes) olarak adlandırılabilir [8].

Ancak taşkın sırasında odunsu materyal ve sedimentlerin bendin ızgaralarını çok hızlı tıkaması nedeniyle, geçirgen tersip bentleri de kısa sürede klasik tersip bendi haline dönüşebilmektedir [9,10], (Şekil 2). Bu da taşkın anında koruyucu özelliğinin yeterli olmamasına sebep olmaktadır. Bu tür durumlar, bazı yönetim sorunlarını da ortaya çıkarmaktadır [11]. Bunlardan biri, etkili bir depolama kapasitesinin sürdürülmesi için bendin memba tarafındaki nehir yatağını temizleme çalışmalarını gerektirmesidir. Bundan dolayı teknik ve ekonomik fizibilitenin değerini azalmış olmaktadır [12,13]. Bu nedenle geçirgen bentler ile sediment akışlarının kontrolü teorik analiz, deneysel çalışmalar ve saha araştırmalarıyla incelenmektedir [5,7,14,15,16,17]. Armanini ve Larcher [14] tarafından gerçekleştirilen laboratuvar deneyleri sonucunda sediment tutma performansını belirlemek için bir tasarım kriteri elde edilmiştir. Farklı geçirgen bent tipleri için de bazı deneysel ve sayısal araştırmalar yapılmıştır [18]. Takahashi vd. [19], Hui-Pang [20] ve Armanini vd. [21], geçirgen bentlerin tuzaklanma ve düzenleyici özelliklerini belirlemek için çalışmalar yapmışlardır. Kanal deneylerine ve sayısal analize dayalı olarak, Shrestha vd. [22], Itoh vd. [23] ve Shima vd. [24] 1zgaralı tip geçirgen bentlerin tuzaklama özelliklerini değerlendirmişlerdir. Ayrıca, geçirgen bentlerin rolünü ve etkinliğini değerlendirmeyi amaçlayan birkaç araştırmacı tarafından farklı indeksler de önerilmiştir [25]. Arazi ve küçük ölçekli modellerin tamamlayıcısı olarak, sediment birikim süreçlerini modellemek için sayısal yaklaşımlar da geliştirilmiştir [5,7,26,27]. Bu çalışmaların tümü, geçirgen bentlerin sediment akışını kontrol etmede hayati bir rol oynadığı ve etkilerinin farklı yöntemler kullanılarak ölçülebileceği sonucuna varmaktadır.

$\mathrm{Bu}$ araştırmaların çoğu yalnızca sediment akışına odaklanmıştır. Ancak dağlık nehir havzalarında odunsu materyaller geçirgen bentlerde sedimentlerden çok daha kısa sürede tutulmakta ve bendin memba tarafını tamamen doldurmakta, hatta bent üzerinden aşarak aşağı havzada yıkıcı etkilere sebep olmaktadır. Bunun için, odunsu malzeme akışının davranışını anlamak ve önleyici tedbirlere odaklanmak taşkın tehlikelerinin azaltılmasında oldukça önemlidir. Bunun için ise, geçirgen bentlerin tasarımı ve işleyişinin anlaşılması iyi bir değerlendirme gerektirir. Ancak, geçirgen bentlerin odunsu materyal tutma verimliliği konusunda çok az araştırma mevcuttur. Maricar ve Hashimato [15] ve Hashimoto vd. [28], deneysel kanal çalışmalarında odun modellerini hareketli yatağa yerleştirerek odunsediment-su karışım akışını oluşturmuşlardır. Laboratuvar kanalında bu karışım için geçirgen bentlerin malzeme tuzaklama verimliliğini incelemişlerdir. Daha güncel olarak, Meninno vd. [29] ve Rossi ve Armanini [30] tarafından yapılan çalışmalarda geçirgen bentlerin işleyişinde 
odunsu materyalin davranışı ve bu yapıların en iyi tasarım parametreleri deneysel olarak araştırılmıştır.
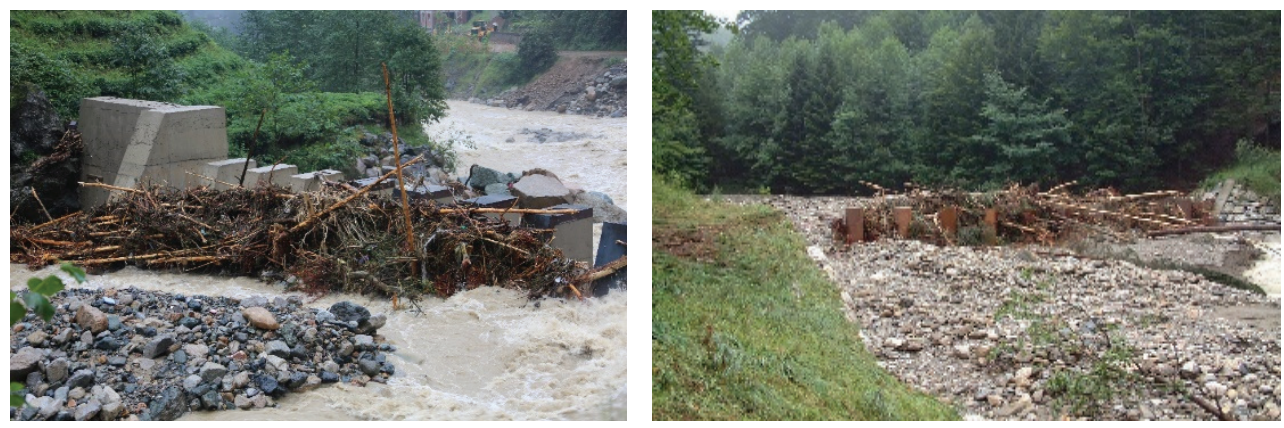

Şekil 2 - Odunsu malzemenin geçirgen bentte birikmesi (Rize Güneysu ve Avusturya Salzburg)

Bu çalışmada, dünyada yaygınlaşmaya başlayan, ancak işletme aşamasındaki hızlı tıkanma mekanizması nedeniyle istenilen işlevi yeterince yerine getiremeyen geçirgen tersip bentlerine alternatif olarak tasarlanan gemiburnu modeli irdelenmiştir. Bu şekilde, klasik biriktirmeli tersip bendi tipinin tasarım amacına hizmet edecek, ancak odunsu materyali de yeterince tuzaklayabilecek ve üstten aşmasını da engelleyecek bir tip tasarımı geliştirilmiştir. Yapının gemiburnu şeklinde modellenmesi sayesinde bendin önüne gelen odunsu materyal, suyun hareketi ile sürekli bir devinime ve yanal deplasmana maruz kalacak ve kısa süredeki tıkanma önlenmiş olacaktır. Bu tipin uygulanabilirliği için de dikdörtgen bir kanalda odunsu malzeme ve sedimentlerle bir dizi deney gerçekleştirilmiştir.

\section{YÖNTEM}

\subsection{Hidrolik Model Düzeneği}

Geçirgen tersip bentlerindeki odunsu malzeme ve sediment ve tuzaklanmasını incelemek için Devlet Su İşleri (DSI) 22. Bölge Müdürlüğü (Trabzon) Hidrolik Model Laboratuvarında bir dizi deney gerçekleştirilmiştir. Deneylerde kullanılan parametreler belirlenirken Doğu Karadeniz Havzasını temsil edebilecek özelliklere sahip Rize ili Taşlıdere Havzası'nın parametrelerinden yararlanılmıştır.

Deney için her iki yanı düz cam olan $14 \mathrm{~m}$ uzunluğunda, $80 \mathrm{~cm}$ genişliğinde ve $25 \mathrm{~cm}$ yüksekliğinde dikdörtgen bir kanal oluşturulmuştur. Kanal için Froude benzeşimine dayalı olarak 1:25 benzerlikte geometrik ölçek kullanılmıştır. Şekil 3, kanalın plan ve boy kesit görünümünü göstermektedir. Kanal yatağı hareketli ve sabit bölümlerden oluşmaktadır. Hareketli yatak $6.1 \mathrm{~m}$ uzunluğunda ve sabit yatak $2.5 \mathrm{~m}$ uzunluğundadır. Sabit yatak, hareketli yatak için kullanılan malzeme ile pürüzlendirilmiştir. Sediment ve odunsu malzemeler hareketli yatağa konulmuş ve geçirgen bent modelleri yatağın sabit kısmına yerleştirilmiştir. 

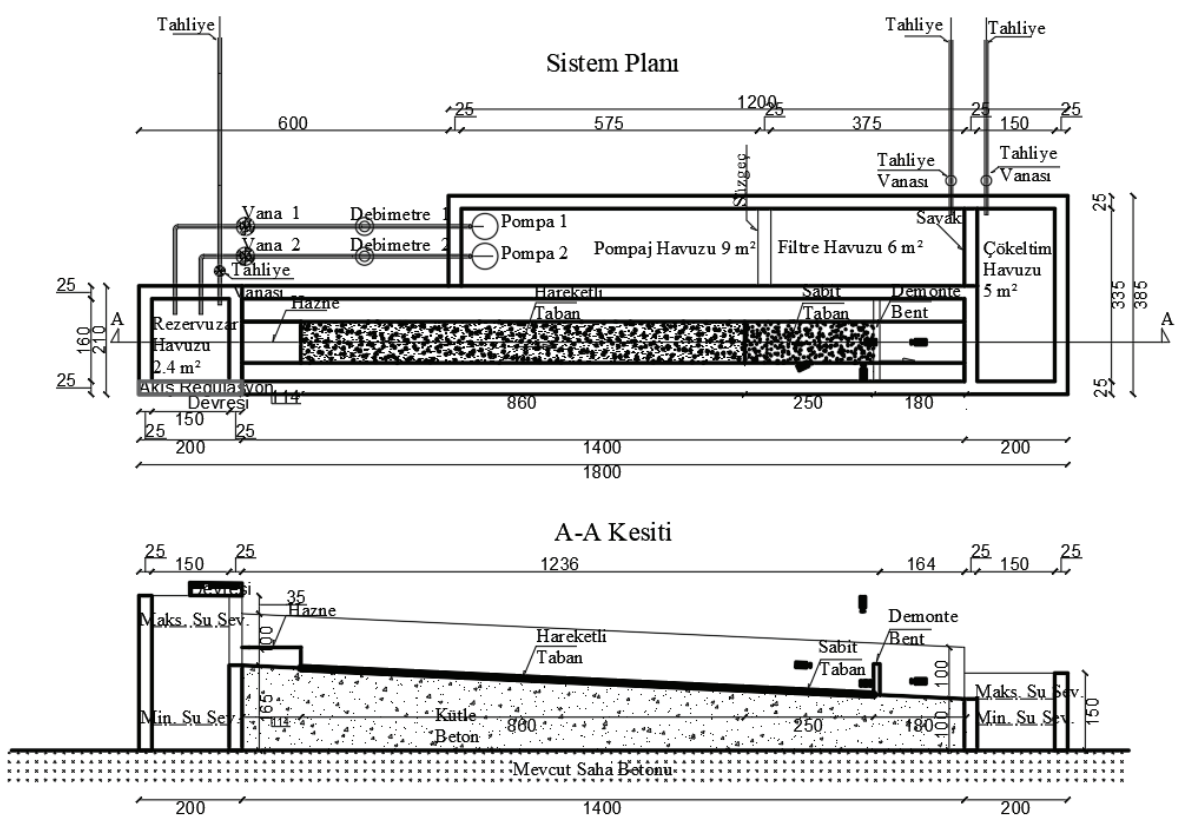

Şekil 3 - Deney kanalı plan ve boy kesiti

Modeldeki su temini kapalı bir devir daim sistemi ile sağlanmış ve borularla pompalanarak yükleme havuzuna getirilmiştir. Havuzdan savaklandırılan su akım kanalına ulaşmaktadır. Besleme borusuna monte edilmiş elektromanyetik debimetre, geçen suyun debisini ölçmekte ve su miktarı istenilen debiye göre uzaktan kumandalı vanalarla ayarlanmaktadır. $\mathrm{Su}$, deney kanalına $2.5 \mathrm{~m}$ uzunluğundaki bir akış düzleştiriciden girmekte ve sonra hareketli yatağa ulaşmaktadır. $6.1 \mathrm{~m}$ uzunluğunda hareketli yatak bölümünden sonra sabit yatak devam etmektedir. Geçirgen bentler, sabit yatağın $2.5 \mathrm{~m}$ mansabında kurulmuştur. Geçirgen bentlerin mansabında 1.80 m uzunluğunda sabit bir bölüm bulunmaktadır. Kanalın çıkışında, bentten geçen odunsu materyal sayılarını belirlemek için materyalleri toplayan bir elek bulunmaktadır. Kanalın mansap ucunda, akış serbestçe bir toplayıcıya düşmekte ve devreyi tamamlamak için depolama tankına geri dönmektedir. Kanal eğimi \% 4 tür. Ölçeklendirme gerçek boyutun 1/25 küçültülmüş halidir. Modelin davranışını kaydetmek için kameralar kanalın üst, sağ ve bentlerin mansap tarafina monte edilmiştir. Kameralar, 1920 x 1080 piksel çözünürlüğe ve saniyede 60 kare (fps) kare hızına sahip Panasonic LUMIX DMC-GH4 modelidir.

\subsection{Kanal Yatağı Malzemesi ve Odun Modelleri}

Deneylerde kullanılan eğim ve odunsu malzemeler için taşkın felaketlerinin sıklıkla meydana geldiği Güneysu Rize, Taşlıdere Nehri, Gürgen Kolu baz alınmıştır. Bu havzanın drenaj alanı yaklaşık $131 \mathrm{~km}^{2}$ dir ve kanalın uzunluğu $23 \mathrm{~km}$ 'dir, eğimi ise ortalama \%10'dur. Bu nehir, Doğu Karadeniz Havzası'ndaki birçok nehri temsil etmektedir. Tersip bentleri ise mümkün 
mertebe düşük eğime sahip (\%2-4) kesimlerde uygulanarak depolama kapasitesinin arttırılması hedeflenmektedir. Hidrolik kanal da bu yüzden \% 4 eğime göre ayarlanmıştır. Bölgedeki taşkınlarda büyük çoğunlukta kızılağaçlar akışla birlikte sürüklenmektedir.

Model odunlar, bölgeyi temsil eden ve özgül ağırlığı $0.68 \mathrm{~g} / \mathrm{cm}^{3}$ olan bu kızılağaçlarından yapılmıştır. Ağaçların yükseklik ve çapları arazi gözlemleriyle belirlenmiş ve Rize'de daha önceki taşkın olayları sırasında gözlemlenen doğal odunsu materyale göre ölçeklenmiştir. Odunların hacmi ve boyutları, havzadaki klasik geçirgen tersip bentinin arkasında biriken odunsu molozlardan hesaplanmıştır. Boy ve çapları 2 farklı silindirik boyutta kullanılmıştır. (Tablo 1). Sediment malzemesi ortalama $\mathrm{d}_{50}=15 \mathrm{~mm}$ çapa, maksimum $\mathrm{d}_{\max }=19 \mathrm{~mm}$ çapa, üniformluluk katsayısı $C_{u}=4.1$ ve eğrilik katsayısı $C_{c}=2.9^{\prime}$ a sahiptir. Hareketli yatak, 2.65 $\mathrm{g} / \mathrm{cm}^{3}$ özgül yoğunluğa sahip sediment karışımı ile doldurulmuştur.

Tablo 1 - Odun modelleri

\begin{tabular}{ccc}
\hline & Çap $(\mathrm{mm})$ & Uzunluk $(\mathrm{cm})$ \\
\hline Odun modeli 1 & 10 & 11 \\
Odun modeli 2 & 15 & 16.5 \\
\hline
\end{tabular}

\subsection{Odunsu Malzeme Hacim Tayini ve Tuzaklama Kapasitesi}

DKH gibi dağlık nehir havzalarında, odunsu malzeme esas olarak taşkınlarla gelmektedir [10]. Köprülerin ve menfezlerin dar bölümleri, odunsu malzeme birikimi için potansiyel alanlardır. Bundan dolayı odunsu malzeme oluşumunun tahmini önem kazanmaktadır. Taşkın özellikleri göz önüne alındığında, beklenen odunsu malzeme hacminin tahmin edilmesi Piton and Reckling [31] çalışmalarında bulunmaktadır.

Odunsu malzemeyi tuzaklamak, aşağı havzadaki yerleşim, altyapı, su yapıları vb. taşkın riskini azaltır ancak, yüksek tuzaklama kapasitesi de bu yapıların kolayca dolmasına ve tasarlanan düzenleme işlevini süratle kaybetmesine neden olur. Bu nedenle geçirgen bentler tasarlanırken makul bir oran belirlemek önemlidir. Tuzaklama kapasitesinin temel indeksi, tuzaklanan ve geçen odunsu malzeme hacimleri arasındaki oran olarak ifade edilir. Detaylı bilgiler Piton and Reckling [31] çalışmalarında bulunmaktadır.

\subsection{Model Bentler ve Önerilen Yeni Tipin Tasarım Kriterleri}

Çalışma kapsamında dünyada kullanılmakta olan 2 farklı tip yarı geçirgen tersip bendi tipi ile bu çalışmada yeni tasarlanan gemiburnu (GB) tip geçirgen tersip bendi kullanılmıştır. Deneylerde kullanılan tüm yarı geçirgen tiplerde gövdenin alt kısmı, askıda olmayan ve sürüklenerek gelen sedimenti tutacak şekilde geçirimsiz (klasik tersip bendi) biçiminde, üst kısmı ise odunsu materyali tuzaklayacak ızgaralardan tasarlanmıştır. Geçirgen bent modelleri geçirimsiz plywood'tan yapılmıştır ve prototiplerin küçültülmüş boyutu $1 / 25$ 'dir. Modellerin yüksekliği $20 \mathrm{~cm}$ ve genişliği 64 cm' dir. Deneylerde kullanılan ve karşılaştırmaya alınan yarı geçirgen tersip bendi hazneli tip 1 (YG1) ve yarı geçirgen tersip bendi hazneli tip 2 (YG2) modellerine ait en kesit görünümü ve çizimleri Şekil 4 ve Şekil 5 'te sunulmuştur. 

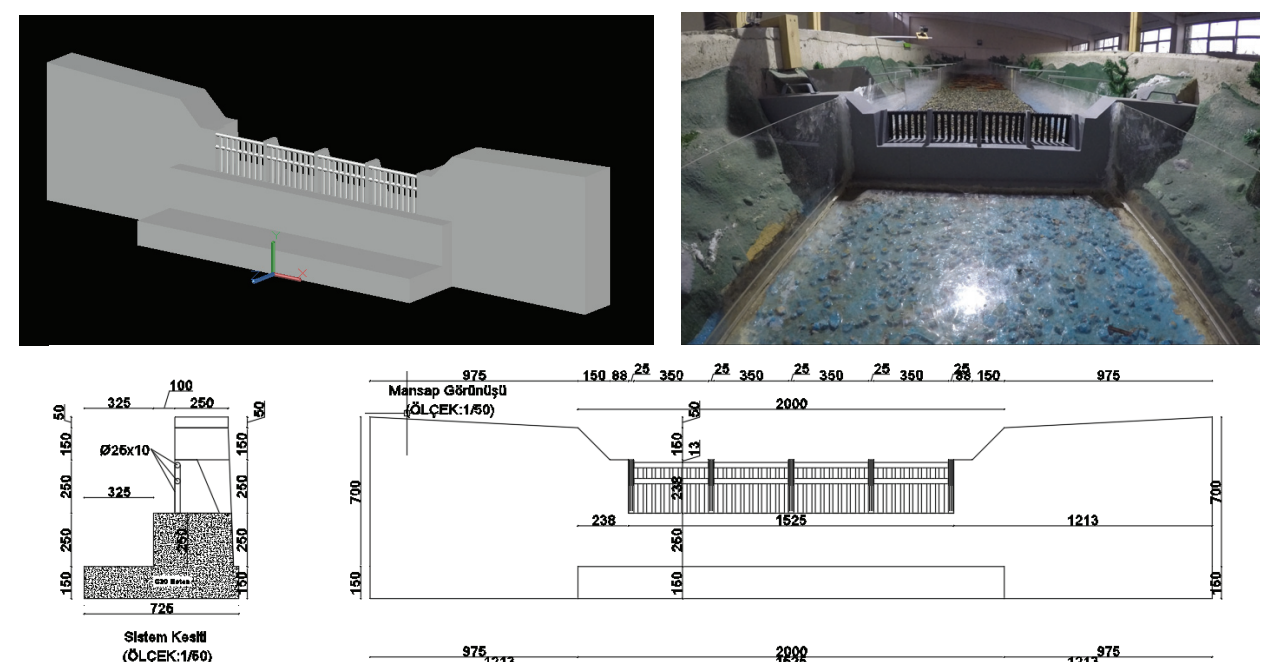

(OLÇЕK:1\%0)

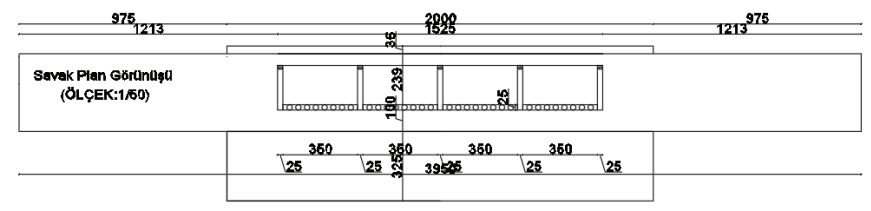

Şekil 4 - YG1 tipine ait çizim ve model enkesit görüntüsü
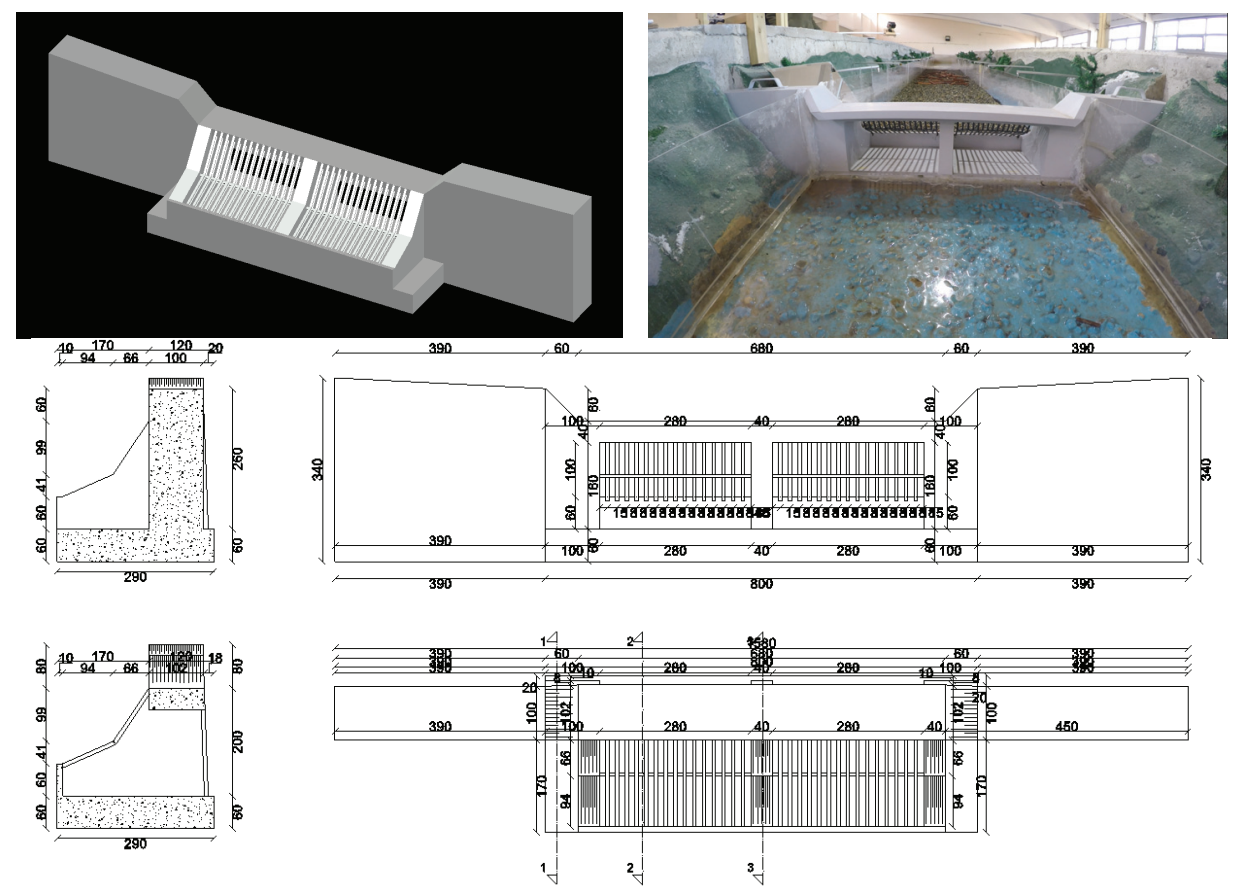

Şekil 5 - YG2 tipine ait çizim ve model enkesit görüntüsü 
Klasik yarı depolamalı geçirgen tersip bentleri, Şekil 5'de görüldüğü gibi suyun akışına dik olarak düzlemsel formda projelendirilmektedir. Bu projelendirme tipi, bende gelen ilk ağaçlardan itibaren hızlı bir yığılmaya ve suyun kuvveti ile sıkışmaya neden olmaktadır. Bunun sonucunda ağaçlar bendi tıkamaktadır. Bu durum ise bendin fonksiyonunu değiştirmekte ve depolamalı geçirgen yerine klasik bent olarak çalışmasına neden olmaktadır. Bu yüzden de hem depolama hacminin üzerinde rüsubat depolaması yapılmakta, hem de tutulması planlanan ağaçlar tıkanma sonrası bendin üzerinden aşmaktadır.

$\mathrm{Bu}$ çalışmada, yarı depolamalı geçirgen tersip bendine alternatif olarak gemiburnu modeli tasarlanmıştır. Bu modelin deney tipine ait en kesit, üst ve mansap görünümü ile deney kanalındaki deney öncesi kamera görüntüleri Şekil 6'da sunulmuştur.

$\mathrm{Bu}$ tasarım ile yarı depolamalı geçirgen tipin tasarım amacına hizmet edecek, ancak su ve askıdaki sediment akımına da engel olmayacak ve odunsu materyalin üstten aşmasını da engelleyecek bir tip tasarımı geliştirilmiştir. Önerilen bu tipin ciddi oranda ağaç tuzaklaması sağlaması, ancak klasik yarı hazneli tipteki gibi tıkanma dezavantajına sahip olmaması amaçlanmıştır. Yapının gemiburnu şeklinde modellenmesi sayesinde bendin önüne gelen odunsu materyal, suyun hareketi ile sürekli ötelenmeye ve bir devinime maruz kalacak, bu sayede orta bölümdeki malzemeler sağ ve sol sahile doğru yönlenecektir. Bunun sonucu olarak bendin önü uzun süre açık kalacaktır. Gemiburnu şeklindeki yapı tasarımı ayrıca odunsu materyalin üstten aşmasına da engel olacaktır.

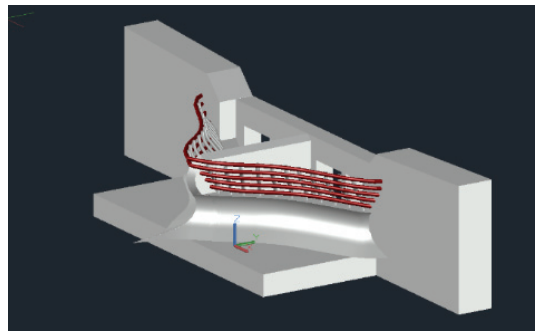

ARKA GÖRÜNŪŞ
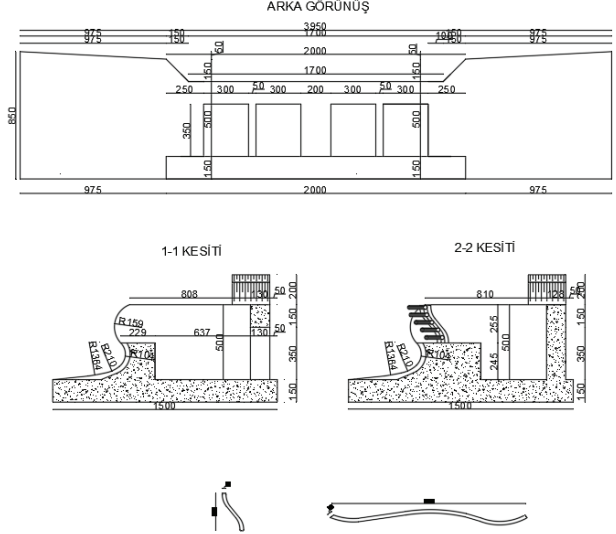
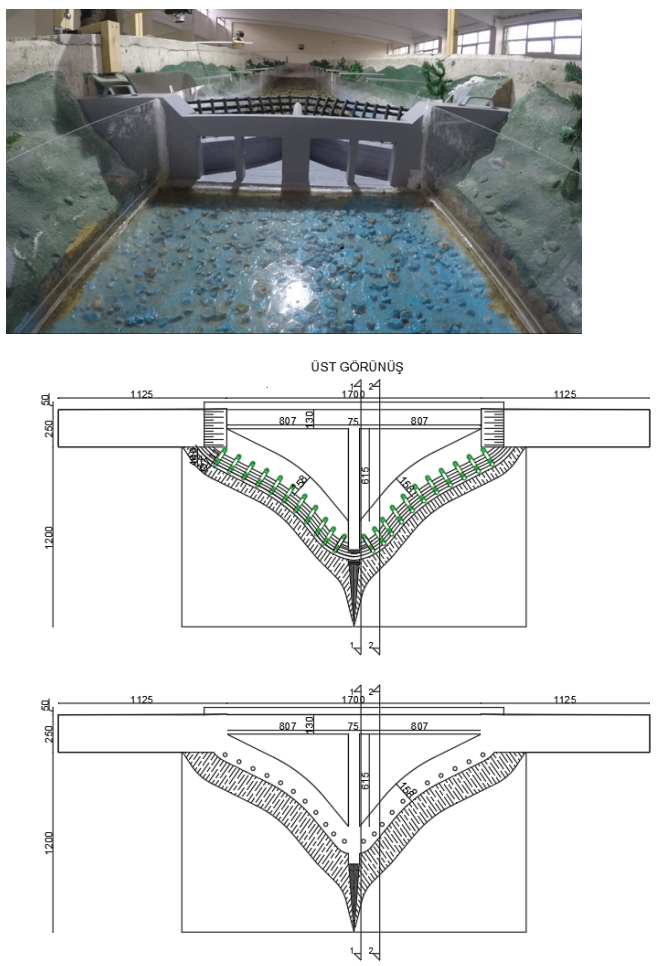

Şekil 6 - Gemiburnu tipine ait çizim ve model enkesit görüntüsü 


\subsection{Deney Programı}

Bu çalışmada önerilen gemiburnu tip geçirgen bendi ile klasik tip bendin sediment ve odunsu malzeme biriktirme kapasitelerini karşılaştırmak ve bent önü tıkanıklığını gözlemlemek için deneyler yapılmıştır (Tablo 2). Hareketli yatak, sediment ve odunsu malzeme ile doldurulmuştur. Model bentler, kanalın aşağı akış ucundan $1.8 \mathrm{~m}$ uzaklıkta sabit yatak üzerinde konumlandırılmıştır. Kanala bent yerleştirilmeden önce akış rejimini gözlemlemek için bir dizi referans testleri yapılmıştır. Her deneyden önce yatak yeniden düzenlenmiş ve tüm deneyler için dağılımının aynı kalmasına özen gösterilmiştir.

Odun sayısının (N) malzeme tutma kapasitesine etkisini belirlemek için $(1$ adet $/(20 * 20) \mathrm{cm}$, 1 adet $/(25 * 25) \mathrm{cm}$ ve $(1$ adet $/ 30 * 30)) \mathrm{cm}$ odun aralıkları için $\mathrm{N}_{1}=172, \mathrm{~N}_{2}=110$ ve $\mathrm{N}_{3}=76$ olmak üzere üç adet $\mathrm{N}$ kullanılmıştır ve buna göre deney setleri oluşturulmuştur. Odun malzemesinin kanal yatağına yerleştirme biçimleri Şekil 7'de görülmektedir. Rize Güneysu Taşlıdere Nehri prototip havza olarak dikkate alınmış ve 500 yıl tekerrür süreli taşkın debisi seçilmiştir. Bu havzadaki geçirgen bendin 500 yıl tekerrür süreli taşkın debisi $\mathrm{Q}_{\mathrm{p}}=72.69$ $\mathrm{m}^{3} / \mathrm{sn}$ iken, model debisi Froude ölçeğine göre $\mathrm{Q}_{\mathrm{m}}=0.02326 \mathrm{~m}^{3} / \mathrm{sn}$ olarak hesaplanmıştır. Bir deney seti 25 saniyede gerçekleştirilmiştir ve sabit debi ile kanal eğimi kullanılmıştır. Daha uzun bir akış süresi, sediment ve odunsu malzemenin birikme profilinin sonuçlarını etkilememiştir. Benzer kanal boyutlarına sahip diğer çalışmalarda, her bir deneysel çalışmanın süresi 8-20 saniye civarında tutulmuştur [15, 17, 28, 32, 33]. Tuzaklanma ve birikme profilleri ölçülmüş ve kameralar tarafından kaydedilmiştir.

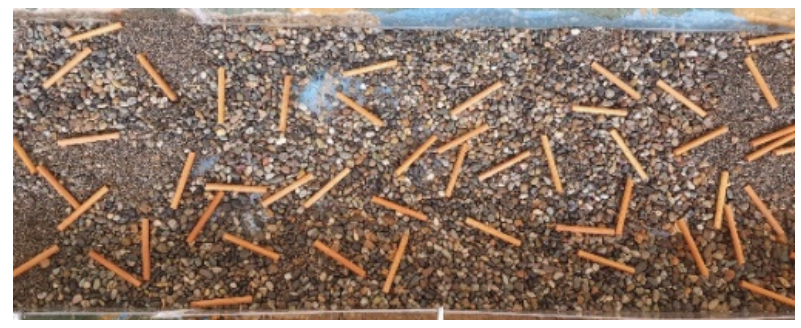

Şekil 7 - Odun malzemesinin kanal hareketli yatağına yerleştirilmesi

Tablo 2 - Deney setleri

\begin{tabular}{cccc}
\hline Senaryo & $\begin{array}{c}\text { Odun uzunluğu, } \\
\text { L (cm) }\end{array}$ & $\begin{array}{c}\text { Odun çap1, } \\
\mathrm{d}(\mathrm{mm})\end{array}$ & $\begin{array}{c}\text { Odun sayıs1, } \\
\mathrm{N}\end{array}$ \\
\hline 1 & 11 & 10 & 172 \\
2 & 11 & 10 & 110 \\
3 & 11 & 10 & 76 \\
\hline 4 & 16,5 & 15 & 172 \\
5 & 16,5 & 15 & 110 \\
6 & 16,5 & 15 & 76 \\
\hline
\end{tabular}




\section{BULGULAR}

Deneylerde elde edilen odunsu materyalin tuzaklanma biçimleri ve bentlerin memba yüzünde oluşan biriktirme profilleri karşılaştırılmıştır. YG1 bent ile yapılan deneylerde önce odunsu materyallerin bentin memba yüzündeki ızgaralarda homojen bir dağılım ile tutulduğu, buna karşın ızgaraları tıkamaya başladığı görülmüştür. Akabinde bendin hızla klasik tersip bendi haline gelmesiyle, yeni gelen odunsu malzemeler üstten aşmaya başlamaktadır (Şekil 8).
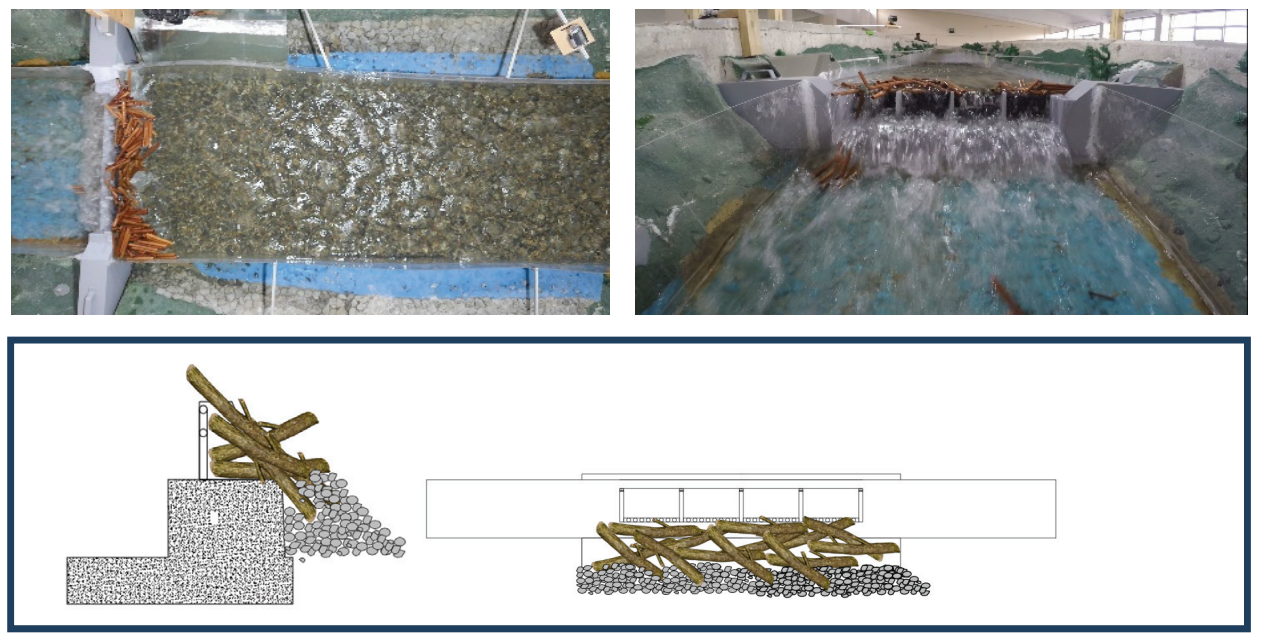

Şekil 8 - YG1 bent malzeme birikme profili
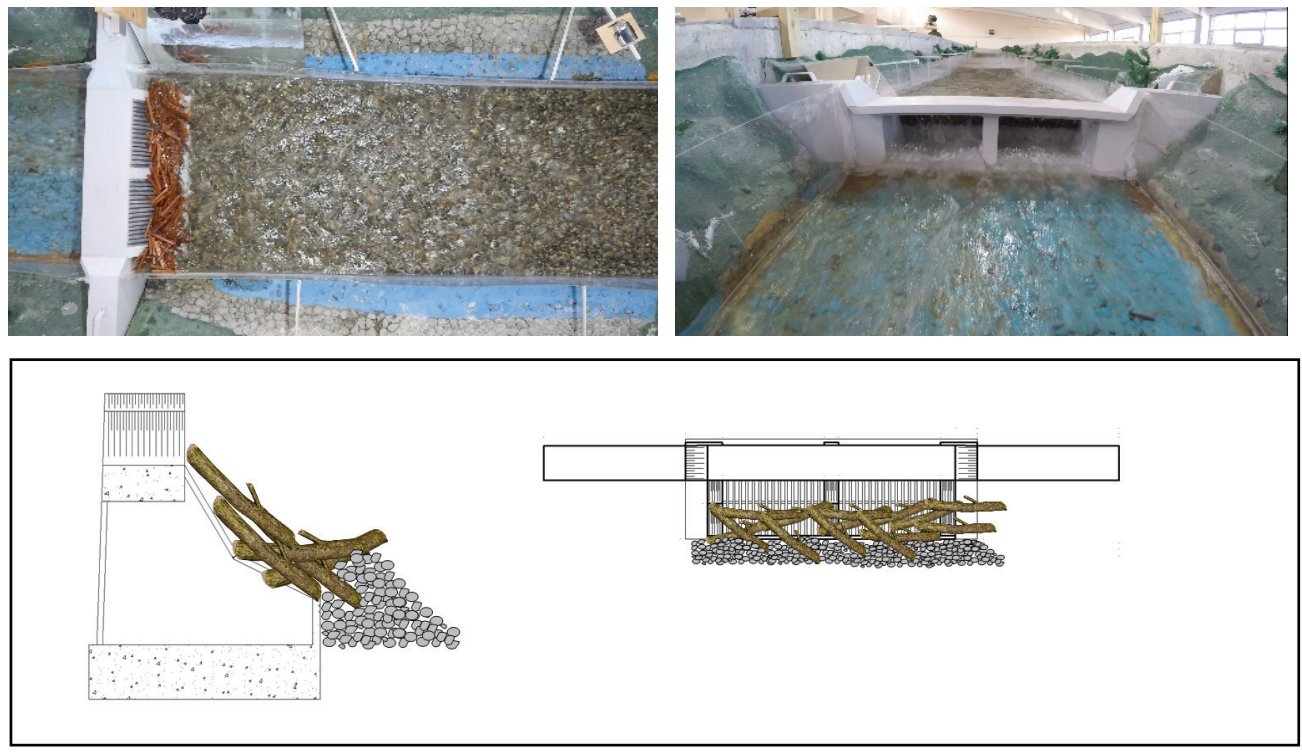

Şekil 9 - YG2 bent malzeme birikme profili 
YG2 bent yap1lan deneylerde odunsu materyallerin bendin memba yüzündeki izgaralarda homojen bir dağılım ile tutulduğu, buna karşın ızgaraları tıkamaya başladığı görülmüştür (Şekil 9). Bu durum bendin hızla klasik tersip bendi haline gelmesine, dolayısıyla geçirimli kesim olarak projelendirilen kısmında geçirimsiz hale gelip sediment ile dolmasına ve yeni gelecek odunsu malzemelerin üstten aşmasına sebep olacaktır.

Gemiburnu tip geçirgen bent ile yapılan deneylerde odunsu materyalin bendin tipi nedeniyle suyun itici gücüyle birlikte sağ ve sol taraflara doğru yığıldığı, bendin önünün tıkanmadığ1 ve bu sayede bendin yarı geçirgen özelliğini sürdürdüğü tespit edilmiştir (Şekil 10). Bu sayede bendin üzerinden de herhangi bir odunsu materyal taşınımı olmadığı tespit edilmiştir.
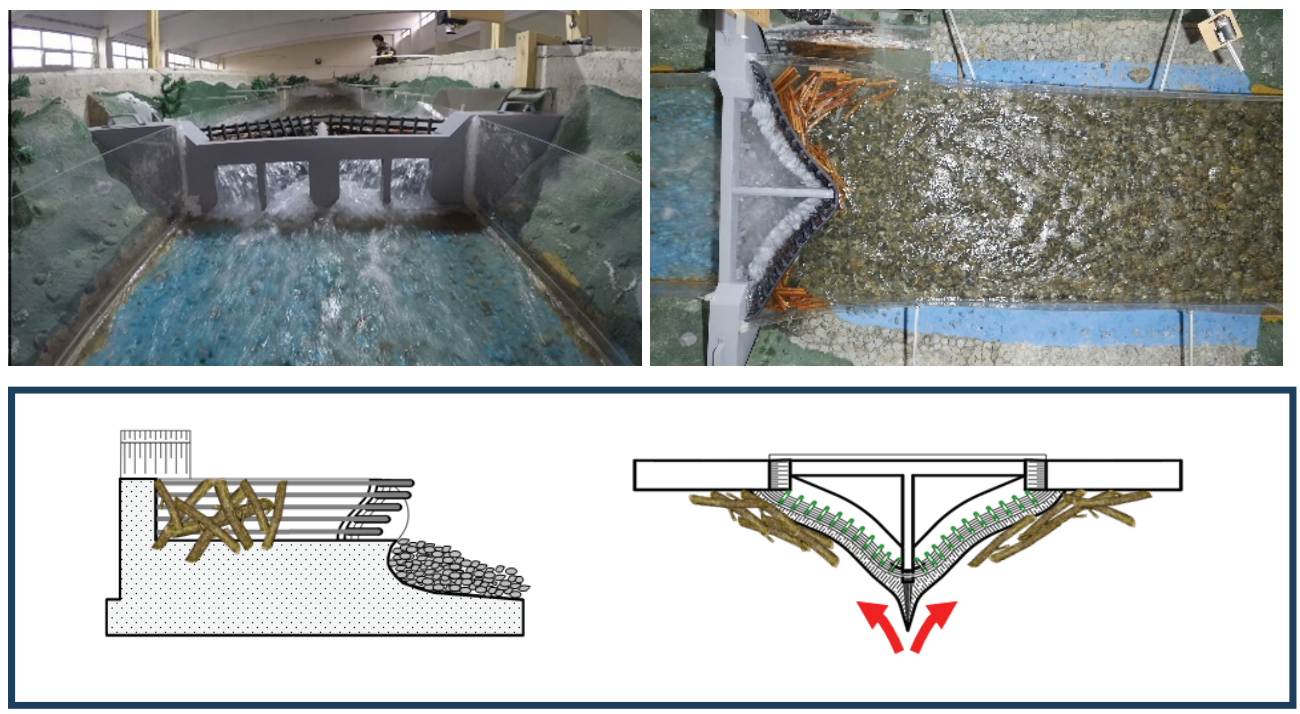

Şekil 10 - Gemiburnu tip geçirgen bent malzeme birikme profili

Gemiburnu tip geçirgen bent ile YG1 bent, odunsu materyalin tuzaklanması için karşılaştırıldığında elde edilen sonuçlar aşağıdaki grafikte sunulmuştur (Şekil 11). Grafikten görüldüğü üzere YG1 bentte odunsu materyalin bazı deney setlerinde \% 30 lara varan üstten aşımı gözlenmiştir. Buna karşın Gemiburnu bent tipinde neredeyse hiç üstten aşım gözlenmemiştir. $\mathrm{Bu}$ sonuçlar, gemiburnu bent tipinin odunsu materyalin üstten aşmama noktasında ne kadar başarılı olduğunu göstermektedir.

Gemiburnu tip geçirgen bent ile YG2 bent, odunsu materyalin ızgaraları tıkaması konusunda karşılaştırıldığında elde edilen sonuçlar aşağıdaki fotoğraflarla sunulmuştur (Şekil 12). Görüldüğü üzere YG2 bentte odunsu materyal bendin 1zgaralarında hızlı bir birikim ve blokaj oluşturmaktadır. Buna karşın Gemiburnu bent tipinde neredeyse ön cephede odunsu materyal birikimi gözlenmemiş, malzeme sağ ve sola yönlenmiş ve bendin önü açık kalmıştır. Bu sayede suyun bent ızgaralarından kolayca akışı devam etmiş ve işletme ömrü uzatılmıştır. 


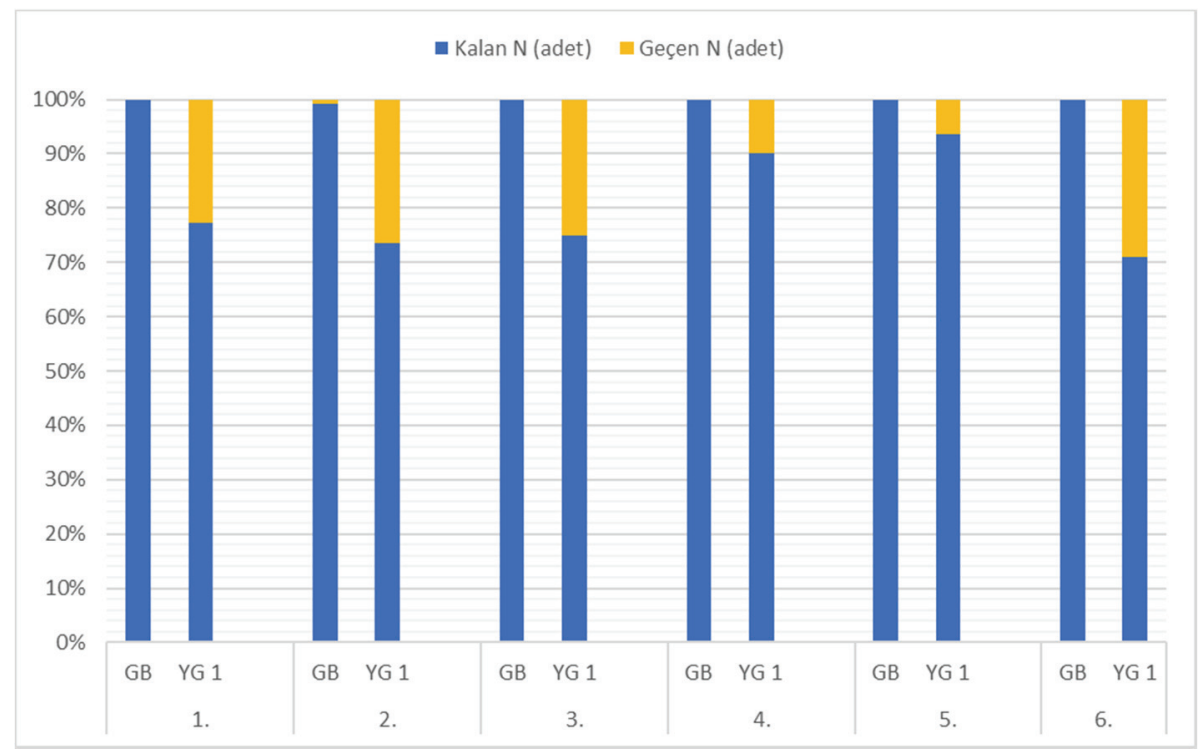

Şekil 11 - Gemiburnu tip geçirgen bent ile YG1 bendin odunsu malzeme tuzaklama karşıllaştırma grafiği


Şekil 12 - Gemiburnu tip geçirgen bent ile YG2 bendin ön cephede odunsu malzeme birikim ve blokaj durumlart

Deneydeki sonuçlar, bentlerin ızgaralarının odunsu materyallerle tıkanması yönüyle karşılaştırıldığında, bendin memba yüzü ile suyun akış yönünün birbirine dik olmasının her halükarda bendin kısa sürede tıkanmasına yol açttğını göstermektedir. Nitekim sahada yapılan uygulamalarda yapılan gözlemlerde de bu sorun tespit edilmiş ve bu çalışma ile soruna çözüm aranmıştır. Gemiburnu tipinden esinlenerek tasarlanan tipte ise odunsu materyalin tüm ızgara boyunca blokaj oluşturmadığı ve böylece "tıkanmadan kaçınma" hedefine ulaşılmış olduğu görülmüştür. Bunun sonucunda hem tıkanma, hem de tıkanmadan dolayı meydana gelebilecek üstten aşma sorununa çözüm bulunduğu görülmüştür. 
Elde edilen tüm bu sonuçlar, gemiburnu bent tipinin odunsu materyalin bendi tıkamama ve üstten aşmama noktasında ne kadar başarılı olduğunu göstermektedir. Bu olumlu sonuçlara istinaden DSİ 22. Bölge Müdürlüğü bünyesinde uygulamaya esas projelendirme çalışmalarına başlanmış olup, inşaat çalışmalarına da kısa zamanda başlanması planlanmıştır.

\section{SONUÇLAR}

Odunsu materyalleri tuzaklayan geçirgen tersip bentleri, sadece taşkın riski altındaki bölgelerde değil, taşkın riskinin nispeten düşük olduğu bölgelerde dahi hayati öneme sahip yapılardır. Nitekim yatak kesitinin yeterli, akarsu debisinin düşük olduğu durumlarda dahi akışlar ile sürüklenen odunsu materyaller, köprü, menfez veya yatak kesitini tıkayarak taşkınlara neden olabilmektedirler. Bu risk, yoğun yağış alan ve taşkın olasılığı daha yüksek yerlerde ise çok daha fazladır.

Son yıllarda dünyada uygulaması sıklaşan geçirgen bentlerde görülmüştür ki, büyük taşkınlarda geçirgen bentler çok kısa sürede odunsu materyallerle tıkanabilmekte ve bu durumda yapıların malzeme tuzaklama ve düzenleme kapasiteleri olumsuz etkilenmektedir.

$\mathrm{Bu}$ çalışmada, bu sorunun önlenmesi adına gemiburnu şeklinde tasarlanmış yeni tip bent, işletme halindeki iki farklı tipteki klasik yarı geçirgen tersip bendi ile laboratuvar ortamında karşılaştırılmıştır. Sonuçlar yeni tipin hızlı tıkanma ve üstten aşma sorununa karşı etkili olduğunu göstermiştir. Bu yapının sahada uygulanmasıyla taşkın zararlarının azaltılması adına önemli bir katkı sağlanmış olacaktır.

\section{Kaynaklar}

[1] Anılan, T., Yüksek, Ö., Perception of Flood Risk and Mitigation: Survey Results From the Eastern Black Sea Basin, Turkey. Natural Hazard Review, 18(2): 05016006, 2017.

[2] Anilan, T., Nacar, S., Kankal, M., Yuksek, O., Prediction of Maximum Annual Flood Discharges Using Artificial Neural Network Approaches. Građevinar, 72(03.), 215224, 2020.

[3] Akçalı, E., Arman H., Yağış Eşiği Bazlı Heyelan Erken Uyarı Sistem Önerisi: Trabzon İli Örneği, İMO Teknik Dergi, 396, 6307-6332, s., 2013.

[4] Akçalı, E., Kuduban, H., Efeoğlu, A., Fakraden, E.Ç., Deniz, S., Yeni Tip Taşkın Kontrol Sistemleri ve Türkiye'deki Uygulama İmkanları, 4. Ulusal Taşkın Sempozyumu, 23-25 Kasim 2016, Rize, 335-346, 2016.

[5] Busnelli, M. M., Stelling, G.S., Larcher, M., Numerical Morphological Modeling of Open-Check Dams. Journal of Hydraulic Enginering, 127(2), 105-114, 2001.

[6] Armanini, A., Larcher, M., Rational Criterion For Designing Opening of Slit-Check Dam. Journal of Hydraulic Enginering, 127(2), 94-104, 2001.

[7] Campisano, A., Cutore, P., Modica, C., Improving the Evaluation of Slit-Check Dam Trapping Efficiency by Using a 1D Unsteady Flow Numerical Model. Journal of Hydraulic Enginering, 140(7), 04014024, 2014. 
[8] Catella, M., Paris, E., Solari, L., Case Study: Efficiency of Slit-Check Dams in the Mountain Region of Versilia Basin. Journal of Hydraulic Enginering, 131(3), 145-152, 2005.

[9] Xie, T., Wei, F., Yang, H., Gardner, J.S., Xi, X., A Design Method for a Debris Flow Water-Sediment Separation Structure. Engineering Geology 220, 94-98, 2017.

[10] Akçalı, E., Taşkın ve Sediment Kontrolünde Yenilikçi Yaklaşımlar. 2. International Natural Disasters and Disaster Management Symposium Proceedings Book, 4-6 May1s 2018, Sakarya, Türkiye, 31-40, 2018.

[11] Comiti, F., Macconi, P., Marchi, L., Arattano, M., Borga, M., Brardinoni , ... and Vischi, M., Debris Flow Monitoring and Warning System: a New Study Site in the Alps. In Work Group F Thematic Workshop on Implementation of the Floods Directive 2007/60/EC, Flash Floods and Pluvial Flooding, 2010.

[12] Schwindt, S., Franca, M.J., Schleiss, A., The Influence of the Opening Width of Check Dams on Bedload Continuity of Mountain Rivers (No. CONF, pp. 1156-1160), 2016.

[13] Petrus, F., Pallu, H. M. S., Thaha, M. A., Maricar, F., Experimental Study on Control of Mixed Debris Flow with the Check Dam Combination. International Journal of Civil Enginering (IJCIET), 10(10):159-166, 2019.

[14] Armanini, A., Dalri, C., Larcher, M., Slit-Check Dams for Controlling Debris Flow and Mudflow. In International Symposium Disaster Mitigation of Debris Flows, Slope Failures and Landslides, Universal Academy Press, Inc (pp. 141-148), 2006.

[15] Maricar, F., Hashimoto, H., A Comparison of Wood-Sediment-Water Mixture Flows at a Closed Type and an Open Type of Check Dams in Mountain Rivers. In River Flow 2014 Conf. Proc (pp. 711-716), 2014.

[16] Piton, G., Recking, A., Design of Sediment Traps with Open Check Dams. I: Hydraulic and Deposition Processes. Journal of Hydraulic Engineering, 142(2), 04015045, 2016.

[17] Yuan, D., Liu, J., You, Y., Zhang, G., Wang, D., Lin, Z., Experimental Study on the Performance Characteristics of Viscous Debris Flows with a Grid-Type Dam for Debris Flow Hazards Mitigation. Bulletin Engineering of Geologic Environment 78(8), 5763 5774, 2019.

[18] Sun, H., You, Y., Li, J. F., Experimental Study on Characteristics of Trapping and Regulating Sediment with an Open-Type Check Dam in Debris Flow Hazard Mitigation. Journal of Material Sciences, 15(9), 2001-2012, 2018.

[19] Takahashi, T., Nakagawa, H., Harada, T., Yamashiki, Y., Routing Debris Flows with Particle Segregation. Journal of Hydraulic Engineering, 118(11), 1490-1507, 1992.

[20] Hui-Pang, LIEN., Design of Slit Dams for Controlling Stony Debris Flows. International Journal of Sediment Research, 18(1), 74-87, 2003.

[21] Armanini, A., Dalri, C., Larcher, M., Slit-Check Dams for Controlling Debris Flow and Mudflow. In International Symposium Disaster Mitigation of Debris Flows, Slope Failures and Landslides, Universal Academy Press, Inc (pp. 141-148), 2006. 
[22] Shrestha, B. B., Nakagawa, H., Kawaike, K., Baba, Y., Numerical Simulation on Debris-Flow Deposition and Erosion Processes Upstream of a Check Dam with Experimental Verification. Disaster Prevention Research Institute Annuals, 51(B):613624, 2008.

[23] Itoh, T., Horiuchi, S., Mizuyama, T., Kaitsuka, K., Hydraulic Model Tests for Evaluating Sediment Control Function with a Grid-Type Sabo Dam in Mountainous Torrents. International Journal of Sediment Research, 28(4), 511-522, 2013.

[24] Shima, J., Moriyama, H., Kokuryo, H., Ishikawa, N., Mizuyama, T., Prevention and Mitigation of Debris Flow Hazards by Using Steel Open-Type Sabo Dams. International Journal of Erosion Control Engineering, 9(3), 135-144, 2016.

[25] Castillo VM, Mosch WM, García CC, Barberá GG, Cano JN, López-Bermúdez F (2007) Effectiveness and geomorphological impacts of check dams for soil erosion control in a semiarid Mediterranean catchment: El Cárcavo (Murcia, Spain). Catena, 70(3), 416-427.

[26] Shrestha, B. B., Nakagawa, H., Kawaike, K., Baba, Y., Zhang, H., Driftwood Deposition from Debris Flows at Slit-Check Dams and Fans. Natural Hazards, 61(2), 577-602, 2012.

[27] Li, S., You, Y., Chen, X., Liu, J., Chen, J., Regulation Effectiveness of a WindowCheck Dam on Debris Flows. Engineering Geology, 253, 205-213, 2019.

[28] Hashimoto, H., Hashimura, K., Nagano, H., Maricar, F., Experimental Investigation into Flow Behavior of Wood-Sediment-Water Mixture at a Grid Type of Open Check Dam. International Journal of Erosion Control Engineering, 9(4), 188-193, 2016.

[29] Meninno, S., Canelas, R. B., Cardoso, A. H., Coupling Check Dams with Large Wood Retention Structures in Clean Water. Environmental Fluid Mechanics, 1-16, 2019.

[30] Rossi, G., Armanini, A., Experimental Analysis of Open Check Dams and Protection Bars Against Debris Flows and Driftwood. Environmental Fluid Mechanics, 1-20, 2019.

[31] Piton, G., Recking, A. Design of Sediment Traps with Open Check Dams. II: Woody Debris. Journal of Hydraulic Engineering, 142(2), 04015046, 2016

[32] Tateishi, R., Horiguchi, T., Sonoda, Y., Ishikawa, N. Experimental Study of the Woody Debris Trapping Efficiency of a Steel Pipe, Open Sabo Dam. International Journal of Sediment Research, 35(5), 431-443, 2020.

[33] Zhou, G. G., Hu, H. S., Song, D., Zhao, T., Chen, X. Q. Experimental Study on the Regulation Function of Slit Dam Against Debris Flows. Landslides, 16(1), 75-90, 2019. 
